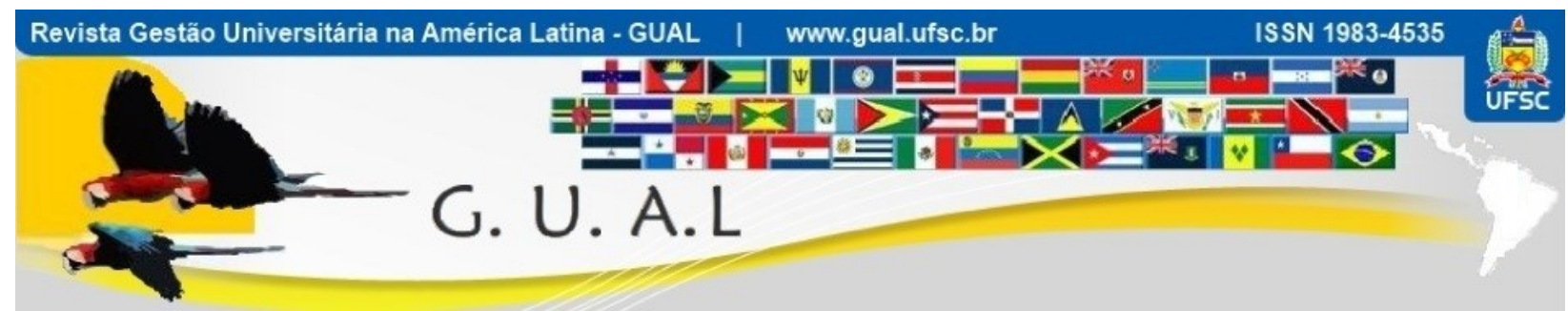

DOI: http://dx.doi.org/10.5007/1983-4535.2018v11n1p253

\title{
TOMADA DE DECISÃO EM ORÇAMENTO: O CASO DA UNIVERSIDADE FEDERAL DE SANTA CATARINA
}

\section{BUDGET DECISION MAKING: CASE OF THE UNIVERSITY FEDERAL OF SANTA CATARINA}

\author{
Verônica de Souza de Melo, Mestra \\ vsouza@,hotmail.com \\ Universidade Federal de Santa Catarina \\ Rogério João Lunkes, Doutor \\ rogeriolunkes@hotmail.com \\ Universidade Federal de Santa Catarina \\ Joice Denise Schäfer, Doutoranda \\ schafer.joice@gmail.com \\ Universidade Federal de Santa Catarina \\ Daiane Antonini Bortoluzzi, Mestra \\ daianeantonini@gmail.com \\ Universidade Federal de Santa Catarina
}

Recebido em 22/setembro/2016

Aprovado em 16/novembro/2017

Sistema de Avaliação: Double Blind Review

Esta obra está sob uma Licença Creative Commons Atribuição-Uso. 


\title{
RESUMO
}

Esta pesquisa tem como objetivo analisar o processo de tomada de decisão orçamentária em uma autarquia universitária federal, de acordo com as premissas conceituais de quatro modelos teóricos de decisão pública: incremental, julgamento seriado, fluxos múltiplos e equilíbrio pontuado. Itens em comum abordados nos modelos permitiram a construção de categorias analíticas norteadoras para a elaboração do instrumento de coleta e análise de dados. Por meio de entrevistas semi-estruturadas e a luz dos modelos teóricos de decisão constatou-se, que no ambiente da instituição analisada, as decisões orçamentárias são tomadas de forma coletiva e focadas no ambiente interno, entretanto, sujeitos externos a organização, tendem a pressioná-la para que novos itens sejam adicionados nas pautas de investimento. Percebe-se uma coexistência dos modelos estudados.

Palavras-chave: Processo Decisório. Orçamento. Desempenho.

\begin{abstract}
This research aims to analyze the process of budget decision-making authority in a Federal University, according to the conceptual premises of four theoretical models of public decision: incremental, trial series, multiple streams and punctuated equilibrium. Items common addressed in models allowed the construction of guiding analytical categories to prepare the instrument for data collection and analysis. Through semi-structured interviews and the light of theoretical models of decision it was found that in the analyzed institution environment, budget decisions are taken collectively and focused manner in the internal environment, however, external organization subjects, tend to press it so that new items are added in the investment guidelines. We can see a coexistence of the models studied.
\end{abstract}

Keywords: Decision Making. Budget. Performance. 


\section{INTRODUÇÃO}

A transparência e a respectiva dinamicidade nas respostas do governo aos problemas do setor público têm, cada vez mais, sido exigidas pela sociedade atual. Diante dessa tendência, os setores da atividade administrativa tomam medidas para implementar melhores práticas, como o sistema orçamentário. O orçamento público serve de instrumento à gestão, ao planejamento e ao controle dos recursos, além de exercer influência direta sobre a economia (GIACOMONI, 1998).

Sob a ótica procedimental o orçamento é um processo mecânico com regras, parâmetros e padrões a serem seguidos, que, no entanto, apresentam múltiplas configurações quando observados pela ótica do processo social (BIN; CASTOR, 2007). Assumindo esta perspectiva, o orçamento vai além da análise quantitativa dos planos orçamentários, e deve buscar a compreensão dos impactos sociais resultantes dos montantes investidos numa ou noutra aplicação. A ampliação da visão da função orçamentária, conforme Abreu e Gomes (2010), depende do amadurecimento dos fundamentos democráticos e da ruptura com o imediatismo político para assumir uma perspectiva de comprometimento social.

Cabe destacar, portanto, que a representação orçamentária engloba um conjunto de dados numéricos classificados de acordo com atividades econômicas, programas políticos entre outras formas, bem como os resultados que os mesmos geram no meio social, ou seja, refere-se a um conjunto amplo de variáveis a serem analisadas e condensadas por um grupo de indivíduos, assim, observado de outro ângulo o orçamento é o resultado de um complexo processo de negociação entre atores com diversos valores, interesses e projetos individuais. $\mathrm{O}$ sistema orçamentário é, portanto, uma arena na qual há uma divisão de poderes entre os agentes, cada qual com valores e preferências particulares (FORTIS, 2009).

No sentido de buscar a compreensão da complexidade envolvida nesta interação social, que leva os agentes a tomarem as decisões relacionadas ao orçamento, modelos para decisão orçamentária, fundamentados na racionalidade limitada, que analisam a incapacidade dos indivíduos de obter e processar todas as informações e consequências da análise de cada alternativa para a tomada da decisão ótima, foram desenvolvidos. Os modelos propostos neste sentido são o incremental (DAVIS; DEMPSTER; WILDAVSKY, 1966), o julgamento seriado (Padgett, 1980), os fluxos múltiplos (KINGDON, 1984) e o equilíbrio pontuado (TRUE; JONES; BAUMGARTNER, 2006). 
Tomando estes modelos como base e tendo em vista o orçamento como um instrumento que influencia o desenvolvimento da sociedade (GIACOMONI, 1998), esta pesquisa tem como objetivo analisar o processo de tomada de decisão orçamentária em uma autarquia universitária federal. As autarquias universitárias federais, são entidades da administração indireta dotadas de autonomia administrativa e financeira para conduzir a política de educação superior brasileira. Ainda que se apresentem diferenças regionais em que se situam, as autarquias públicas universitárias possuem o mesmo tratamento legal, o que não as distingue quando se trata da gestão. Sendo assim, este trabalho foca em uma entidade, a Universidade Federal de Santa Catarina (UFSC).

Este estudo apresenta-se como uma oportunidade de verificar a política orçamentária desenvolvida em um ambiente que impacta diretamente um direito básico da sociedade brasileira, a educação pública, no sentido de identificar a existência do zelo pela perenidade da instituição no longo prazo e do alinhamento de interesses nas ações da instituição. Ademais, a comparabilidade entre a teoria e a prática orçamentária, que este estudo promove é uma contribuição para o desenvolvimento da Universidade, pois na medida em que a pesquisa lança a discussão do tema proporciona a construção e evolução de ideias pelos gestores e servidores e constrói um caminho para a avaliação da efetividade da Universidade no uso dos recursos públicos. Por outro lado, o estudo contribui para o desenvolvimento da teoria quando aprofunda a discussão das decisões orçamentárias dando enfoque à administração indireta, em especial autarquias, o que possibilita a compreensão mais completa da realidade e a futura emersão de novas categorias e conceitos capazes de melhor contribuir para a gestão pública.

\section{PROCESSO ORÇAMENTÁRIO E OS MODELOS DE DECISÃO}

Nas palavras de Fortis (2009, p. 125-126) “[...] o orçamento é espaço decisório no qual o poder é distribuído entre atores sociais dotados de valores, preferências e projetos específicos"; é justamente por conta destas características, somadas a complexidade dos fatores envolvidos no sistema orçamentário, como a ampla gama de opções para os investimentos que "possuem pouco ou quase nenhum apoio em teorias que possam prever as consequências das alternativas (baseadas em preferências) ou a probabilidade de sua ocorrência" (ABREU; GOMES, 2013), e às limitações físicas e psicológicas dos indivíduos em processar informações, que a capacidade de maximização e tomada de decisão a partir de 
um rol de alternativas é reduzida (VALLE; FROSSARD; CRUZ, 2010, p. 2) que as mudanças nos processos orçamentários se tornam difíceis e lentas, ainda que todos os agentes percebam a necessidade de aperfeiçoamento das técnicas e métodos.

Neste sentido, quatro modelos teóricos voltados para a tomada de decisão na alocação de recursos são propostos: o modelo incremental (DAVIS; DEMPSTER; WILDAVSKY, 1966), o julgamento seriado (PADGETT, 1980), os fluxos múltiplos (KINGDON, 1984) e o equilíbrio pontuado (TRUE; JONES; BAUMGARTNER, 2006). Estes assumem a incapacidade humana de onisciência sobre todos os fatores e condições que intervêm para alcance da solução ótima (baseado na racionalidade limitada de Herbert Simon), deste modo, as quatro abordagens partem da prerrogativa de buscar a melhor alternativa dentre as reconhecíveis como adequadas à resolução do problema cientes das limitações informacionais e temporais. $\mathrm{Na}$ sequência estes modelos são melhor detalhados.

\subsection{MODELO DE RACIONALIDADE INCREMENTAL}

O modelo de racionalidade incremental fora aplicado para a questão orçamentária a partir da formulação teórica de Lindblom (1959). O autor defende que as decisões incrementais são na verdade mais comuns que as decisões racionais-compreensivas ou sinópticas, devido a incapacidade humana de percepção de todas as alternativas e das consequências de sua adoção, além da limitação quanto ao tempo e à disponibilidade de recursos e da complexidade dos problemas.

Para Davis, Dempster e Wildavsky (1966), há uma interiorização por parte de cada participante no processo decisório orçamentário de manutenção do padrão de escolhas pela própria dificuldade de revisão completa do valor de todos os programas. Com isso as decisões representam pequenos e simples acréscimos ou decréscimos utilizados como ajustes mútuos para salvaguardar a estabilidade institucional. As sucessivas decisões incrementais constituem-se em um método simples baseado na experiência obtida no passado por parte dos participantes. Estas experiências tornam-se regras para decisões futuras e eventualmente incluem um ajuste levando em conta circunstâncias especiais.

O modelo de decisão orçamentária da racionalidade incremental considera que as decisões orçamentárias são políticas e ocorrem num ambiente de estabilidade no qual as alocações são lineares dada a complexidade do processo orçamentário (NEIVA; LIMA; ABREU, 2012). Apesar da regra de decisão no modelo incremental ser linear, Valle, Frossard 
e Cruz (2010) destacam que, há subsidiariamente a definição de uma variação na alocação de recursos que não é determinística, e sim estocástica, pois os eventos que irão definir o incremento (ajuste) são aleatórios, podendo relacionar-se com mudança de gestão, variações das condições econômicas ou outras.

Davis, Dempster e Wildavsky (1966) evidenciam um modelo de decisão que tende a manutenção dos programas orçamentários a partir de uma visão compartilhada pelos diversos atores do processo orçamentário sobre as expectativas políticas e sociais. Barcelos (2008) aponta esta característica como uma crítica deste modelo por não estimular propostas orçamentárias inovadoras que possam apropriar os recursos de modo melhor.

\subsection{MODELO DO JULGAMENTO SERIADO}

O modelo do julgamento seriado é uma abordagem de decisão orçamentária desenhada por Padgett (1980) como alternativa ao modelo de decisório incremental (VALLE; FROSSARD; CRUZ, 2010). Padgett (1980) observou que o contexto no qual ocorrem as decisões tem influência significativa sobre as decisões orçamentárias, pois inclui no processo dimensões substantivas, administrativas, políticas e econômicas, não consideradas no modelo incremental.

Para Padgett (1980) caracteriza o modelo do julgamento seriado em duas fases; a primeira pelo levantamento de alternativas, quando o participante do processo irá iniciar sua análise a partir de um ponto fixo relacionado as bases históricas orçamentárias anteriores, assim como no modelo incremental, e a segunda pelo julgamento informado resultando na seleção da alternativa; a diferença está na sequência, em que o participante passa a buscar conscientemente alternativas que tanto podem aumentar como reduzir o orçamento. "O rol de alternativas levantadas são limitados pelos condicionantes legais e técnicos, e representam os preconceitos sobre a questão em decisão, o clima fiscal institucionalizado além das opiniões do decisor sobre os méritos do programa" (PADGETT, 1980, 357).

Valle, Frossard e Cruz (2010) explicam que no julgamento seriado o ponto de partida é a avaliação sobre o aumento ou a redução na alocação de recursos a determinado programa. Em seguida, os atores utilizam-se de critérios como metas fiscais e prioridades para fundamentar suas decisões. Por fim, tem-se a decisão sobre o grau do aumento ou redução do orçamento para o programa com vistas a alcançar seu objetivo. 
De acordo com Neiva, Lima e Abreu (2012) a alternativa a ser escolhida será a primeira que cumpre os requisitos técnicos e políticos do agente, observando, segundo Valle, Frossard e Cruz (2010), o ambiente ecológico em que as decisões são tomadas e incluindo a análise estatística para avaliação dos eventos estocásticos, no entanto, novamente não há uma maximização das escolhas orçamentárias, mas sim, uma alternativa que satisfaz da melhor forma o tomador de decisões.

\subsection{MODELO DOS FLUXOS MÚLTIPLOS}

A abordagem dos fluxos múltiplos procura explicar como problemas e soluções são combinadas em uma decisão, considerando as inúmeras opções possíveis de alocação dos recursos. Este modelo, proposto por Kingdon (1984) inspira-se na proposição teórica de Cohen, March e Olsen (1972) ("modelo da lata de lixo") e reconhece a complexidade ambiental, os interesses variados dos participantes e a limitação do tempo, estruturando-se sobre três fluxos que quando se cruzam em termos de atenção pública dá-se a decisão.

O estudo de Cohen, March e Olsen (1972), que influenciou o modelo de fluxos múltiplos, considera as teorias de decisão racionais conflitantes com a forma como as organizações realizavam suas escolhas, e por esta razão estes autores desenvolveram uma pesquisa, partindo do levantamento das características que evidenciam a ambiguidade e a incerteza organizacional - meio este em que as deliberações de fato ocorrem. Os autores referem-se à organização como anarquia organizada, na qual os seus membros têm preferências inconsistentes e mal definidas por determinados problemas, sendo a ação mais reveladora das preferências do que as suas declarações, portanto, para a compreender a tomada da decisão é necessário clarificar os processos que levam a identificação dos problemas, a mobilização de pessoal, a produção de soluções e as oportunidades de escolha.

Kingdon (1984) utiliza-se desta mesma concepção de tomada de decisão, afastando-se do modelo racional-compreensivo em que as deliberações são ordenadas e sequenciadas, e mostra a importância dos fluxos de problemas, de alternativas e político para a definição da agenda. Em suma, Valle, Frossard e Cruz (2010) indicam que o fluxo dos problemas compreende a defesa de atores sobre a urgência da solução de determinada questão; o fluxo das soluções relativo às alternativas de políticas avocadas por pessoas ou grupos interessados em sua promoção; e o fluxo da política relativo a própria dinâmica do contexto político no 
qual são feitas coalizões e ajustamentos nas propostas decidindo assim quais problemas e alternativas de solução receberão a alocação de recursos.

Outro importante conceito adicionado nesta abordagem é o da janela de oportunidades. Trata-se de períodos curtos de tempo em que a atenção pública volta-se para alguma questão por razões políticas, casos fortuitos ou de força maior e isto torna mais fácil a inclusão destes problemas e soluções na agenda formal (VALLE; FROSSARD; CRUZ, 2010).

\subsection{MODELO DO EQUILÍBRIO PONTUADO}

O modelo do equilíbrio pontuado, elaborado por True, Jones e Baumgartner (2006), assume que governos e instituições políticas sofrem de limitação de atenção do mesmo modo que as pessoas; o que prejudica o processo cognitivo amplo de escolhas ótimas. O equilíbrio pontuado é definido por Neiva, Lima e Abreu (2012) como um modelo para entender como as decisões políticas ocorrem, propiciando períodos de estabilidade combinados com alguns períodos de "terremoto" - mudanças rápidas e significativas.

Valle, Frossard e Cruz (2010) explicam que a teoria se desenvolve sobre a interação entre subsistemas políticos, que são representações com delegação do governo para processamento das informações e em paralelo a variação no equilíbrio entre eles e a relação com a macropolítica. Segundo True, Jones e Baumgartner (2006), os subsistemas de políticas representam divisões institucionais responsáveis pelo processamento de informações, de modo paralelo, cuja competência foi atribuída pela macropolítica por não conseguir processar todas as questões. Na macropolítica, por sua vez, o processamento é serial e os subsistemas assumem o papel de análise das informações e definição de novas alternativas.

Assim, enquanto os participantes do subsistema acordarem sobre a questão, existe um monopólio de política, as mudanças são incrementais e estáveis; todavia, quando os atores excluídos do monopólio de política passam a pressionar a macropolítica exigindo mudanças, as questões sobem para a agenda mais ampla e são conduzidas de forma serial para mudanças em larga escala e alteração das estruturas de poder (VALLE; FROSSARD; CRUZ, 2010).

True, Jones e Baumgartner (2006) explicam que há uma mobilização política que sobrepõe as jurisdições formais. Esta sobreposição ocorre em função dos interesses que unem os grupos independentemente de sua localização. Quando cidadãos discordam da imagem do monopólio de política, a mobilização habilita novos participantes a entrarem na discussão, alterando o equilíbrio de poder e das regras. Se a questão alcançar atenção para além do 


\section{TOMADA DE DECISÃO EM ORÇAMENTO: O CASO DA UNIVERSIDADE FEDERAL DE SANTA \\ DOI: http://dx.doi.org/10.5007/1983-4535.2018v11n1p253}

subsistema, ela é instrumento de pressão para entrar na agenda governamental da macropolítica e ser tratada de modo serial. No entanto, não há como fazer previsões de quando ocorrerão tais situações e quais serão seus resultados.

No Quadro 1, apresenta-se uma descrição resumida dos modelos de racionalidade de decisão orçamentária apresentadas, com as principais características que aproximam ou afastam cada modelo.

Quadro 1 Comparativo entre os modelos para decisão orçamentária.

\begin{tabular}{|c|c|c|c|c|}
\hline Dimensões & Incremental & Julgamento Seriado & Fluxos Múltiplos & Equilíbrio Pontuado \\
\hline 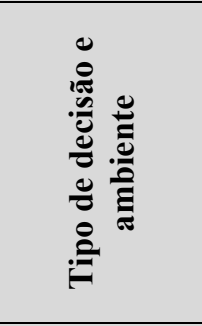 & $\begin{array}{l}\text { Coletiva, em } \\
\text { ambiente } \\
\text { organizacional }\end{array}$ & $\begin{array}{l}\text { Ambiente de incerteza, } \\
\text { decisão sobre poucas } \\
\text { alternativas. Considera } \\
\text { ambiente externo. }\end{array}$ & $\begin{array}{c}\text { Ambiente de disputas de } \\
\text { alternativas e questões. A } \\
\text { decisão resulta da } \\
\text { oportunidade e influência } \\
\text { de atores combinado com } \\
\text { fluxo de problemas e } \\
\text { político. }\end{array}$ & $\begin{array}{c}\text { Individual nos } \\
\text { subsistemas; coletiva na } \\
\text { macropolítica. O } \\
\text { ambiente apresenta a } \\
\text { construção de imagens } \\
\text { pelos subsistemas e } \\
\text { competição de imagens } \\
\text { na macropolítica. } \\
\end{array}$ \\
\hline : & $\begin{array}{c}\text { Os papéis são } \\
\text { Institucionais e } \\
\text { agregam as } \\
\text { preferências dos } \\
\text { diversos atores, tais } \\
\text { como gestores, } \\
\text { parlamentares, } \\
\text { lobby e grupos de } \\
\text { pressão. } \\
\end{array}$ & $\begin{array}{l}\text { Os setores e órgãos } \\
\text { influenciados por } \\
\text { atores internos } \\
\text { eexternos. }\end{array}$ & $\begin{array}{c}\text { Atores visíveis ou não } \\
\text { influenciam.Movimentaç } \\
\text { ãodos grupos depressão } \\
\text { para o porem-se ou } \\
\text { apoiar asquestões, } \\
\text { sinalizandoconsenso } \\
\text { ouconflito na seleção de } \\
\text { alternativa. }\end{array}$ & $\begin{array}{c}\text { Grupos de interesse } \\
\text { desempenhampapel } \\
\text { importantena definição } \\
\text { dasquestões que poderão } \\
\text { chegar } \\
\text { aoambientemacropolítico } \\
\text {. }\end{array}$ \\
\hline 竞 & Serial e fracionado & Serial & Serial & $\begin{array}{c}\text { Serial na macropolítica; } \\
\text { paralela / descontinuada } \\
\text { nos subsistemas }\end{array}$ \\
\hline 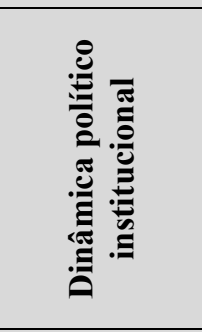 & $\begin{array}{c}\text { Variação marginal } \\
\text { emrelação a } \\
\text { umabase } \\
\text { previamenteexistent } \\
\text { e. }\end{array}$ & $\begin{array}{l}\text { Decisão } \\
\text { condicionadapor vários } \\
\text { atoresdo ambiente } \\
\text { externo. Sequência de } \\
\text { escolhas ordenadas } \\
\text { emvários níveis. }\end{array}$ & $\begin{array}{l}\text { Sofre a influência de } \\
\text { grupos de pressão; das } \\
\text { alterações no humor } \\
\text { nacional e das reformas } \\
\text { administrativas que } \\
\text { alteram a estrutura de } \\
\text { poder. }\end{array}$ & $\begin{array}{c}\text { O contexto político e } \\
\text { institucional influencia } \\
\text { adefinição dealocações. } \\
\text { Se período de } \\
\text { estabilidade variação } \\
\text { incremental, se período } \\
\text { de mudanças variação } \\
\text { mais expressiva. }\end{array}$ \\
\hline 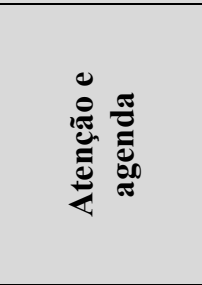 & $\begin{array}{c}\text { Os papéis e as } \\
\text { regras determinam } \\
\text { a atenção e os } \\
\text { problemas que } \\
\text { comporão a agenda. }\end{array}$ & $\begin{array}{l}\text { Há um processo de } \\
\text { investigação sequencial } \\
\text { de prioridades da } \\
\text { agenda a partir da base } \\
\text { de alocações pré- } \\
\text { existente. }\end{array}$ & $\begin{array}{l}\text { Problemas entram na } \\
\text { agenda por avaliação dos } \\
\text { seus indicadores, por } \\
\text { situações de crises, pela } \\
\text { avaliação de programas; } \\
\text { desde que alcancem a } \\
\text { atenção pública. }\end{array}$ & $\begin{array}{l}\text { As questões se tornam } \\
\text { problemas quando as } \\
\text { imagens chamam } \\
\text { a atenção do } \\
\text { sistema macropolítico. }\end{array}$ \\
\hline
\end{tabular}

Fonte: Adaptado de Valle, Frossard e Cruz (2010, p. 9-10). 
Observa-se que a análise dos modelos possibilitou a construção de cinco categorias analíticas (tipo de decisão e ambiente, participantes, processamento das informações, dinâmica político institucional e atenção e agenda) presentes nos modelos, que nortearam a elaboração do instrumento de coleta de dados da Universidade Federal de Santa Catarina.

\section{METODOLOGIA}

O ambiente da pesquisa foi a Universidade Federal de Santa Catarina, que possui campus em Araranguá, Curitibanos, Florianópolis e Joinville. Tendo em vista que as principais decisões de planejamento e orçamento da Universidade estão situadas no campus de Florianópolis, definiu-se o mesmo como unidade de análise. Para fins de aplicação da pesquisa foram selecionados os gestores que compõem a administração central, uma vez que estes são responsáveis pela coordenação das ações orçamentárias, além de responderem pelo gerenciamento dos recursos sob o enfoque macro, possibilitando uma visão ampliada da destinação dos recursos. A composição da amostra com todas as pró-reitorias e secretarias oportuniza a representação das percepções das distintas áreas da Universidade.

As entrevistas tiveram a duração de 35 minutos à 1 hora e dez minutos. Em razão do compromisso assumido com os entrevistados não serão divulgados os nomes, mas apenas o cargo ocupado pelos mesmos, assim como não será feita a identificação na análise dos dados. Das 11 pessoas inicialmente selecionadas uma recusou-se a participar da pesquisa após conhecer o tema e o roteiro de entrevista sob a justificativa de que não teria as informações que estavam sendo coletadas. O Secretário de Aperfeiçoamento Institucional delegou a participação na pesquisa ao seu Assistente e a entrevista referente à Secretaria de Cultura, em razão das férias do Secretário, contou com uma entrevista com dois respondentes, a Secretária Adjunta e a Servidora responsável pela gestão financeira da secretaria. Os participantes selecionados para a pesquisa a partir do seus cargos foram:

- Pró-Reitor de Planejamento e Orçamento

- Pró-Reitor de Administração

- Pró-Reitor de Assuntos Estudantis

- Pró-Reitor de Extensão

- Pró-Reitor de Pesquisa

- Pró-Reitor de Pós-Graduação

- Servidor Assistente do Secretário de Aperfeiçoamento Institucional

- Secretário Adjunto de Cultura e Servidora Adm. Financ.

- Secretário de Gestão de Pessoas

- Secretário de Relações Internacionais 
A pesquisa foi desenvolvida por meio de uma entrevista semi-estruturada, ou seja, utilizou-se de um roteiro com questões que orientaram a entrevistadora, sobre as dimensões a serem exploradas. O roteiro incluiu oito blocos, os dois primeiros com questões relacionadas as características sócio-demográficas dos entrevistados além da sua ocupação profissional na Universidade e também as características gerais do processo orçamentário da sua unidade; dos blocos três ao sete foram analisadas as categorias analíticas construídas a partir dos modelos estudados (incremental, julgamento seriado, fluxos múltiplos e o equilíbrio pontuado. O bloco oito reuniu duas perguntas de encerramento que contribuíram para identificar a relação que os profissionais estabelecem entre orçamento e o desempenho da Universidade. A apreciação de conteúdo foi realizada a partir da transcrição das entrevistas, as quais foram analisadas de acordo com as categorias teóricas analíticas apresentadas no Quadro 1.

\section{RESULTADOS EMPÍRICOS}

A análise do processo decisório do orçamento da Universidade Federal de Santa Catarina está pautada em quatro teorias de decisão específicas da administração pública que consideram a racionalidade limitada no processo de tomada de decisão, mais propriamente do processo de orçamento público. As teorias utilizadas são: incremental, julgamento seriado, fluxos múltiplos e equilíbrio pontuado. Foram elencadas cinco categorias analíticas, com diferentes características representativas presentes em todos os modelos para a discussão do orçamento, assim, cada uma destas categorias é analisada, na sequência, em consonância com os dados coletados na Universidade e com as perspectivas abordadas nos modelos.

\subsection{TIPOS DE DECISÃO E AMBIENTE}

A dimensão "tipo de decisão e ambiente" tem por objetivo analisar como ocorre o processo decisório referente ao processo de orçamento da UFSC, centrando-se na compreensão do ambiente que interfere na tomada de decisões orçamentárias, observando se há na análise para as deliberações inclusão do ambiente externo, buscando captar a complexidade das decisões no que se refere a deliberações tomadas individualmente ou de modo coletivo com inclusão de pessoas além daquelas que representam papéis formais.

Todos os entrevistados apontaram que existe uma tomada de decisão do tipo coletiva na elaboração e execução do orçamento, onde um grupo ou colegiado discute os recursos necessários a serem alocados nas previsões realizadas, informando à PROPLAN das 
demandas necessárias. Entretanto, a eficácia dessa discussão coletiva fora questionada por diversos entrevistados, ora caracterizando-a como informativa (entrevistado 1), ora apontando que a matriz orçamentária está muito defasada (entrevistados 2,5 e 7 ).

Para o entrevistado 8 a decisão na elaboração do orçamento é coletiva e a questão de mais ou menos participação depende da gestão e do interesse da comunidade como um todo: "Esse é um processo então que tem que ser construído; não só a partir da gestão, mas envolvendo a comunidade como um todo, do ponto de vista das representações sociais que compõem a comunidade acadêmica se fazerem valer e ter voz para todo esse debate."

O ambiente da tomada de decisão também foi relatado por todos os entrevistados como sendo o ambiente interno/organizacional. Nove dos dez entrevistados afirmaram que não existe uma análise do ambiente externo no processo decisório referente a elaboração e execução do orçamento, todavia as categorias referentes as teorias do julgamento seriado e equilíbrio pontuado não podem ser afastadas porque percebe-se pelas falas dos entrevistados 6 e 7 em especial, em outro momento da entrevista, que o contexto ecológico influencia as decisões, ainda que gerem ações e dispêndios orçamentários sem continuidade no longo prazo.

Os entrevistados 6 e 7 reconhecem afirmativamente a influência do meio externo sobre o ambiente de tomada de decisão, mas informam que é a dinâmica das pressões e da política institucional que determinará qual o nível de investimento que a questão receberá. $\mathrm{O}$ entrevistado 7 reconheceu que o ambiente externo é levado em consideração em outros tipos de decisão tomadas na sua unidade, mas não referente a orçamento/questões financeiras. $\mathrm{O}$ entrevistado 9 revelou que faz um monitoramento do ambiente externo apenas para verificação de editais e captação de recursos, que incrementam o orçamento da sua unidade, porém para a elaboração do orçamento da UFSC/MEC não há uma análise externa.

Nessa dimensão, conforme Neiva, Lima e Abreu (2012) e Valle, Frossard e Cruz (2010), a teoria de fluxos múltiplos e o incremental não são excludentes, e pelo relato dos entrevistados apresentam evidências de complementação. Apesar dos entrevistados questionarem a pouca autonomia do orçamento da UFSC, suas falas dentro do tópico "tipos de decisão e ambiente" conduzem para o caráter histórico e incremental do orçamento de suas unidades (pró-reitorias e secretarias), reconhecendo um ambiente de disputa pelos recursos, e valendo-se de argumentações racionais no momento da solicitação de recursos adicionais. 


\subsection{PARTICIPANTES}

Nessa dimensão foram investigados quais são e como participam os atores que exercem influência no processo de elaboração e execução do orçamento da UFSC. Todos os entrevistados afirmaram que os principais atores que exercem influência sobre o orçamento atuam institucionalmente, ou seja, são em sua maioria membros internos da universidade, como professores, pró-reitores, diretores de centro, servidores técnicos, etc.

Quanto aos membros externos, possuem uma posição institucionalizada nas câmaras e comissões temáticas, como por exemplo, representantes dos discentes nas câmaras de pósgraduação ou representantes da comunidade na comissão de cultura na Universidade.

Os grupos de pressão foram igualmente reconhecidos como atores que se unem em torno de uma causa e tentam influenciar a elaboração ou execução do orçamento com diversas argumentações. O entrevistado 6 reforçou o ambiente de disputa no processo decisório do orçamento da UFSC, trazendo à tona o exemplo de uma manifestação dos representantes dos estudantes no ano de 2005. Nesse episódio os estudantes interromperam os acessos à reunião do Conselho Universitário (CUn), impedindo a saída dos participantes da reunião, até que suas reivindicações fossem atendidas. Recentemente os estudantes se mobilizaram para o fim da contrapartida laboral nas bolsas do tipo permanência, tendo êxito no seu pleito, conforme entrevistado 6 .

Nesse ponto os entrevistados 3 e 10 trouxeram exemplos de participação de membros externos à Universidade que não estão representados na estrutura formal de decisão da UFSC. O exemplo das emendas do orçamento da Universidade por parlamentares, como a recente emenda de um deputado, para construção de um espaço físico para o programa de Engenharia e Gestão do Conhecimento. E o caso em que representantes da comunidade do bairro, solicitaram audiências e reuniões com a reitoria da Universidade a respeito de um terreno da UFSC que era do interesse deles. Segundo o entrevistado, essa pressão resultou em discussões dentro da estrutura de tomada de decisão da UFSC, que podem gerar impactos diretos ou indiretos no orçamento da Universidade.

Nesta dimensão de análise é possível perceber a existência de atores formais e institucionalizados como sendo o padrão mais presente no relato dos entrevistados. Reconhece-se, todavia, os grupos de pressão, ainda que oito dos entrevistados tenham relatado apenas atores internos ou institucionalizados. Esse padrão está relacionado com a teoria incremental, no qual "os papéis são institucionais e agregam as preferências dos diversos 
atores, tais como gestores, parlamentares, lobby e grupos de pressão" (NEIVA; LIMA; ABREU, 2012; VALLE; FROSSARD; CRUZ, 2010).

Entretanto, não se pode ignorar a influência de atores e grupos de pressão externos que não participam da estrutura de decisão formal da UFSC, como demonstrou o relato dos entrevistados 3 e 10. As demais teorias analisadas abordam a participação de grupos externos não institucionalizados no processo de tomada de decisão, sendo a teoria do julgamento seriado a mais objetiva, ao afirmar que o orçamento responde mais fluidamente a influências externas (políticas) do que o previsto na teoria incremental, que prevê um comportamento eminentemente incremental, tendendo a neutralizar os fatores causais dos pontos de mudança (shift points), segundo Padgett (1980).

\subsection{PROCESSAMENTO DAS INFORMAÇÕES}

Nesta dimensão de análise buscou-se verificar a maneira como ocorre o processamento das informações no processo de elaboração e execução do orçamento da UFSC. A categorização utilizada para classificação do processamento das informações no orçamento público, proposta por Neiva, Lima e Abreu (2012), trabalha com três variáveis (processamento serial, fracionado e paralelo), as quais quando combinadas podem apontar para a predominância de uma teoria em relação a outra

O relato de todos os entrevistados indica a existência de um processamento seriado, com verbas orçamentárias sendo tratadas e discutidas uma a uma, centralizadas na PROPLAN, sobretudo as verbas que impactam a Universidade como um todo. Entretanto, cada unidade é responsável por estudos, levantamentos e propostas de novas dotações, realizando um processamento de informações na execução do orçamento das atividades orçamentárias atinentes a sua pró-reitoria ou secretaria, sobretudo aquelas de custeio.

Assim fica caracterizado a existência de um padrão duplo, sendo um serial e outro que pode ser fracionado, o que implicaria num padrão incremental, ou paralelo, apontando para o equilíbrio pontuado. Ainda que o padrão verificado no relato dos entrevistados seja duplo, não é possível descartar por completo as teorias de julgamento seriado e fluxos múltiplos, haja vista que estas também apresentam o padrão de processamento seriado e podem representar de maneira mais adequada este padrão.

Desse modo fez-se necessário explorar os motivos que levam ao padrão de processamento serial em cada teoria e a diferenciação do padrão fracionado e paralelo, de 
modo a verificar o padrão que melhor se adequa ao orçamento da UFSC na dimensão do processamento das informações. De acordo com o relato dos entrevistados, 5, 7 e 9 é perceptível a existência de pressões, seja de indivíduos ou grupos, para alterações orçamentárias, o que não condiz com um padrão regular e sem grandes variações.

A justificativa da teoria do julgamento seriado também não explica o processamento serial das informações da UFSC. Segundo Padgett (1980), a teoria do julgamento serial pressupõe que o processo orçamentário também parte de uma base fixa e estável, a partir da qual é tomada uma decisão de acrescer ou diminuir as dotações, de forma binária. A complexidade da tomada de decisão no orçamento geral da UFSC ultrapassa a simplicidade de uma análise binária, haja vista a utilização de análises, estudos e planejamento para elaboração e execução do orçamento.

A teoria dos fluxos múltiplos explica que os processamentos das informações são seriais, pois os tomadores de decisão ocupam-se de poucas questões ao mesmo tempo, e para que uma questão seja aceita e incorporada ao orçamento, é necessário que um problema obtenha atenção do tomador de decisão ligando-se a uma solução efetiva. Em relação ao processamento das informações esse padrão não restou caracterizado no relato dos entrevistados.

De acordo com o relato dos entrevistados foi possível perceber a existência de um ambiente de pressão nos subsistemas que refletem em questões orçamentárias. Desse modo, em relação a dimensão "processamento das informações", a teoria do equilíbrio pontuado mostra-se mais adequada ao padrão do processo orçamentário da UFSC, com processamento seriado e centralizado na PROPLAN, e um processamento paralelo junto às demais unidades orçamentárias.

\subsection{DINÂMICA POLÍTICO INSTITUCIONAL}

A dimensão denominada "dinâmica político institucional" procura analisar como ocorrem as variações do orçamento e quais fatores e atores exercem influência nestas alterações.

Os 10 entrevistados confirmaram a existência de uma base orçamentária que possui um crescimento contínuo e de base histórica, principalmente aquelas que se referem ao custeio. Segundo o entrevistado 3, a UFSC vem se expandindo constantemente e não existe um setor que esteja se retraindo. O entrevistado afirma que é muito difícil de abandonar um 
contrato ou uma despesa, o que ocorre são remanejamentos e substituições.

A definição do valor a ser alocado no orçamento das instituições de ensino superior tem como base a arrecadação da União, podendo variar para mais ou para menos conforme os rumos da economia do país, segundo os entrevistados. Os entrevistados não entraram no mérito dos critérios da matriz ANDIFES, apenas ratificaram que esse tem sido o parâmetro para definir o orçamento da Universidade. Os entrevistados 3 e 8 apontaram que além do comportamento da arrecadação e dos critérios da matriz ANDIFES existem outros fatores que influenciam no orçamento da Universidade, como a influência que a bancada de parlamentares catarinenses no Congresso Nacional exerce na consignação de recursos extraordinários ao orçamento da UFSC, por exemplo. Esse tipo de emenda coletiva no orçamento acontece por uma pressão da Universidade junto aos parlamentares, e, segundo o entrevistado 3, é liderada pela própria reitoria.

Além dos recursos destinados pelo MEC (matriz ANDIFES), e das emendas dos parlamentares, existe ainda a captação de recursos para projetos específicos. Os entrevistados 5 e 6 afirmaram que essa fonte de recursos é obtida através da participação em editais lançados por instituições de fomento à pesquisa e extensão como o CNPQ, CAPES, FINEP, FAPESC, entre outras. Para esses recursos, segundo os entrevistados, não existe uma lógica de planejamento, pois muitos deles são alocados diretamente na conta dos pesquisadores ou das fundações de apoio já com o fim específico do projeto.

Segundo o entrevistado 5 os recursos extras, em geral, também são influenciados por pressões externas como o desenvolvimento de uma política pública nova ou a necessidade de empresas estatais desenvolverem novas tecnologias, como por exemplo o caso da política que vem sendo adotada em relação ao pré-sal que exige a criação de novas tecnologias. Os entrevistados 1, 2, 3, 6, 7 e 10 também salientaram que a Universidade vem sofrendo uma variação de orçamento não incremental devido a política de governo de expansão do ensino de educação superior através do REUNI, no qual são priorizadas ações orçamentárias ligadas a criação de novos cursos. O entrevistado 7 atribuiu, ainda, algumas variações no orçamento devido a política adotada por cada gestão, ou seja, por cada reitor.

Internamente, na alocação de recursos do orçamento junto as pró-reitorias e centros, existe, também, um ambiente de disputa por recursos, de acordo com os entrevistados 1,7 e 8 . Os entrevistados 1 e 8 afirmam que existe uma articulação na busca de recursos orçamentários que faz alterar o montante destinado a cada unidade. Os centros de ensino tecnológicos e da 
saúde foram citados pelo entrevistado 8 como exemplos de centros historicamente articulados junto a setores econômicos e políticos, assim conseguem captar mais recursos para dentro da Universidade. Segundo o entrevistado 8 "isso se transformou num poder político interno dentro da Universidade, que faz com que suas demandas, vamos dizer entre aspas, "tenham mais força".

Os incentivos à pesquisa, através de editais de instituições de fomento, apesar de não estarem diretamente ligados ao orçamento da UFSC o influencia indiretamente, pois resulta em atividades de pesquisas e extensão que podem demandar ações orçamentais de conservação e manutenção, por exemplo. No ambiente interno (pró-reitorias e secretarias) o orçamento também segue uma base histórica, mas possui um ambiente de articulação política na busca por recursos orçamentários, como levantado pelos entrevistados 1 e 8 .

Este padrão de dinâmica político institucional contém traços do modelo incremental, mas afasta essa teoria por conter uma dinâmica que vai além da variação marginal em relação a uma base previamente existente. A teoria do julgamento seriado também está contemplada parcialmente no padrão de dinâmica político institucional do orçamento da UFSC, devido a este sofrer variações condicionadas por atores do ambiente externo. Entretanto, não foi verificada uma sequência de escolhas ordenadas em vários níveis, mas sim um processo de tomada de decisão mais dinâmico, com articulações políticas internas e externas.

A teoria dos fluxos múltiplos de Kingdon (1984), afirma que variações ocorrem por influência de grupos de pressão, das alterações do humor nacional e das reformas administrativas. A influência dos grupos de pressão ficou caracterizada através das políticas de incentivo à pesquisa em determinadas áreas e internamente através das articulações dos centros de ensino para garantirem maiores recursos orçamentários. A concepção do termo reforma administrativa, segundo Kingdon (1984), está ligada a mudanças na estrutura de poder, com a alternância dos atores políticos. A influência da reforma administrativa fica caracterizada pela influência da gestão do governo Luiz Inácio Lula da Silva e Dilma Vana Rousseff, que proporcionaram um aumento no orçamento das IFES desde o exercício de 2009, através do programa REUNI, e também internamente, pela influência da política adotada por cada Reitor.

A teoria de equilíbrio pontuado de True, Jones e Baumgartner (2006) afirma que as variações no orçamento sofrem a influência do contexto político e institucional, e afirma que as variações são incrementais quando existe um período de estabilidade e ocorrem variações 
mais expressivas quando a instituição passa por um período de mudanças. Nessa dimensão, quando aplicada ao orçamento, os autores explicam que as variações seguem uma lógica de estabilidade e incremental e são interrompidos por rápidas mudanças, pois algumas questões se tornam rapidamente importantes.

\subsection{ATENÇÃO E AGENDA}

A dimensão "Atenção e Agenda" centra-se em entender como o foco é colocado sobre determinadas questões e como elas são incluídas na agenda, tornando-se alvo de discussão orçamentária. Todas os entrevistados destacaram que determinadas questões entram na agenda de discussão do orçamento devido ao seu caráter histórico, inclusive determinadas ações mais pontuais, como projetos desenvolvidos regularmente por cada pró-reitoria e secretaria.

É possível inferir por meio do relato dos entrevistados 2, 3, 5, 7, 8 e 10 que os papéis institucionais são capazes de influenciar a agenda formal do orçamento. O entrevistado 7 afirma que as modificações realizadas pelos gestores ocorrem, mas são superficiais. O entrevistado 8, por sua vez afirma que no início do segundo semestre é realizada uma reunião com a PROPLAN, onde o gestor pode propor novas prioridades para o orçamento daquele ano, solicitando alterações no orçamento.

Dentre os entrevistados, nove comentaram sobre o papel exercido pela mídia para trazer questões à atenção pública, e que algumas destas questões acabam entrando na agenda formal do orçamento. Entretanto, o entrevistado 9 destacou a necessidade de que as críticas levantadas pela mídia de um modo geral precisam ter fundamentos para que sejam discutidas no âmbito do orçamento, e caso não tenha, ela é apenas justificada e nenhuma outra ação é tomada. O entrevistado 2 destacou o papel dos órgãos de controle como determinantes da agenda.

Os entrevistados 3, 6 e 7 apontaram que muitos problemas são importantes, e têm destaque na atenção pública, mas não entram na agenda porque cedem sua vez a problemas urgentes. O entrevistado 6 destaca que um aumento de pressão, tende a tornar o problema urgente.

Valle, Frossard e Cruz (2010) e Neiva, Lima e Abreu (2012) afirmam que o modelo incremental não possui uma definição de agenda, pois as decisões são tomadas com base em papéis e regras e não se tomando por base os problemas. Nesse sentido, para o incremental 
não há um fluxo no orçamento no qual as questões tomam a atenção pública e entram para agenda formal.

No caso do orçamento da UFSC, mesmo que ele siga regras pré-determinadas e tenha uma base que varia historicamente de forma incremental, sofrendo influência dos papéis institucionalizados, como dos gestores, por exemplo; há uma influência determinada também pela atenção pública na definição de agenda. Deste modo, a teoria incremental, apesar de estar contida na dimensão "atenção e agenda", não é aderente ao padrão verificado na UFSC.

Na teoria do julgamento seriado, conforme Padgett (1980), o orçamento segue uma lógica sequencial na busca de alternativas, buscando aumentar ou diminuir a base de maneira incremental e discreta, percorrendo alternativas vizinhas, até que se encontre uma que seja aceitável e adequada, tanto tecnicamente (que atenda a ação orçamentária) quanto no contexto de restrição fiscal. Seguindo esse fluxo é que as questões adentrariam na agenda formal. Entretanto esse padrão não foi o identificado no processo de orçamento da UFSC através das entrevistas.

Kingdon (1984), com relação a teoria dos fluxos múltiplos, afirma que quando questões se tornam foco da atenção pública existe a abertura de uma janela de oportunidade para que aqueles que defendem a priorização de determinado problema possam associar a resolução do problema a uma solução, alterando a agenda formal do orçamento. A avaliação de indicadores, situações de crise e avaliação dos programas poderiam despertar a atenção pública.

$\mathrm{Na}$ teoria do equilíbrio pontuado, existe a formação de imagens ou símbolos que chamam a atenção de atores até então indiferentes a certas questões orçamentárias e os mobiliza para uma mudança de agenda (PADGETT, 1980). Na teoria do equilíbrio pontuado, a mídia tem um papel influente, direcionando a atenção dos atores e fazendo com que eles mudem a atenção de uma questão para outra.

Na sequência, apresenta-se a Quadro 2, como um quadro resumo dos achados da pesquisa, caracterizando os modelos encontrados na UFSC dentro da análise de cada uma das categorias analíticas pré-estabelecidas.

A Quadro 2 permite evidenciar que a tomada de decisão no orçamento público da UFSC está imersa em um processo complexo, com evidências de sobreposição de vários modelos teóricos. Ainda que os modelos analisados contenham algumas semelhanças entre si, e algumas destas busquem complementar as anteriores, não foi possível determinar a 
predominância de um único padrão para todo o processo de tomada de decisão no orçamento da Universidade.

Quadro 2 Padrão UFSC de decisão orçamentária conforme modelos teóricos

\begin{tabular}{|c|c|c|}
\hline Características & $\begin{array}{c}\text { Modelos } \\
\text { Identificadas }\end{array}$ & Padrão Orçamento UFSC \\
\hline $\begin{array}{c}\text { Tipo de decisão e } \\
\text { ambiente }\end{array}$ & $\begin{array}{c}\text { Incremental } \\
\text { e fluxos múltiplos }\end{array}$ & $\begin{array}{c}\text { Tipo de decisão: Coletiva. Ambiente: } \\
\text { organizacional com disputa de } \\
\text { alternativas e questões. }\end{array}$ \\
\hline Participantes & $\begin{array}{c}\text { Incremental e equilíbrio } \\
\text { pontuado }\end{array}$ & $\begin{array}{c}\text { Papéis e atores institucionalizados e } \\
\text { grupos de interesse com capacidade de } \\
\text { influenciar positivamente a agenda. }\end{array}$ \\
\hline $\begin{array}{c}\text { Processamento das } \\
\text { informações }\end{array}$ & Equilíbrio pontuado & $\begin{array}{c}\text { Serial na macropolítica e } \\
\text { paralela/descontinuada nos subsistemas. }\end{array}$ \\
\hline $\begin{array}{c}\text { Dinâmica político } \\
\text { institucional }\end{array}$ & $\begin{array}{c}\text { Pariações incrementais nas bases de } \\
\text { julgamento seriado, fluxos } \\
\text { múltiplos e equilíbrio } \\
\text { pontuado }\end{array}$ & $\begin{array}{c}\text { mudanças nas bases de capital, } \\
\text { influenciadas pelo desempenho da } \\
\text { universidade (matriz ANDIFES), grupos } \\
\text { de pressão, reformas administrativas e } \\
\text { articulações político/institucionais. }\end{array}$ \\
\hline Atenção e agenda & Equilíbrio pontuado & $\begin{array}{c}\text { As questões se tornam problemas } \\
\text { quando as imagens chamam a atenção do } \\
\text { sistema macropolítico. }\end{array}$ \\
\hline
\end{tabular}

Fonte: Elaborado pelos autores (2016).

\section{CONCLUSÃO}

Identificada a importância do sistema orçamentário, com relação aos impactos que traz para a sociedade, este estudo propôs-se a analisar o processo decisório do orçamento em uma autarquia da área de educação no Brasil, a Universidade Federal de Santa Catarina. Para isso foram utilizados quatro modelos teóricos explicativos, quais sejam: Incremental de Davis, Dempster e Wildavsky (1966), Julgamento Seriado de Padgett (1980), Fluxos Múltiplos de Kingdon (1984) e Equilíbrio Pontuado de True, Jones e Baumgartner (2006). Os quatro modelos são fundamentados na racionalidade limitada, ou seja, assumem a incapacidade humana de onisciência sobre todos os fatores e condições que intervêm para alcance da solução ótima, no entanto, os dois primeiros possuem um enfoque na identificação dos parâmetros normalizadores do orçamento, enquanto os outros dois modelos concentram-se em compreender como a agenda de discussões formais do orçamento é construída.

Cada um dos modelos teóricos observa o tipo de decisão e o ambiente, os participantes, o processamento das informações, a dinâmica político institucional e a forma 
como a atenção é dirigida e a agenda é formada, de forma distinta. Nesse sentido, essas dimensões foram estabelecidas como características para análise das particularidades encontradas na autarquia estudada, em confronto com os modelos teóricos explicativos.

Quanto ao tipo de decisão e ambiente os modelos que melhor representaram os achados, foram o incremental e os fluxos múltiplos, pois ao mesmo tempo em que o ambiente informado nas entrevistas foi o ambiente interno organizacional as decisões foram ditas como tomadas coletivamente, ainda que a participação seja fluída.

Com relação aos participantes, o padrão UFSC de tomada de decisão orçamentária mostrou-se dominado pelos atores que exercem papéis institucionalizados, incluindo nesse grupo representantes dos diversos setores que compõem a comunidade universitária. Os grupos de pressão também foram identificados nas falas dos entrevistados, como intervenientes na orientação orçamentária, o que levou a dimensão a ser identificada com as teorias incremental e de equilíbrio pontuado.

O processamento das informações mostrou-se seriado tanto nas unidades quanto na condução das questões da Universidade como um todo. As unidades são incumbidas da condução de determinadas questões e quando as decisões saem das condições regulares, elas são conduzidas para a administração central, entrando assim em uma agenda própria nesse nível. A partir dessa análise observou-se que a teoria que mais se identifica com esse padrão é a do Equilíbrio Pontuado, pois no conjunto as unidades processam as informações em paralelo e a administração central de modo seriado.

A dinâmica político institucional da UFSC mostra-se compatível sob algum aspecto com cada uma das teorias. Da variação incremental a partir das bases orçamentárias de exercícios passados à períodos de mudanças radicais pela implementação de políticas públicas de governo, passando ainda por articulações político-institucionais e outras variações orçamentárias em decorrência da participação em editais. Sem um predomínio em um dos modelos teóricos nesta dimensão o padrão da Universidade é parcial de incremental, julgamento seriado, fluxos múltiplos e equilíbrio pontuado.

A análise da dimensão atenção e agenda, mostrou que em condições regulares a atenção é direcionada aos programas que formam a base histórica orçamentária, no entanto, os papéis institucionais, grupos de interesse, mídia e órgãos de controles através da associação de ideias a imagens representam forças capazes de reorientar a atenção. Deste modo a teoria que mais se aproxima é o Equilíbrio Pontuado. 
Diante da análise de cada uma das dimensões não é possível afirmar que o modelo de decisão orçamentário da UFSC coincide com uma das teorias, mas que coexistem características do incremental, do julgamento seriado, do fluxos múltiplos e do equilíbrio pontuado em todo o processo orçamentário, demonstrando, assim, que os modelos teóricos propostos por Davis, Dempster e Wildavsky (1966), Padgett (1980), Kingdon (1984) e True, Jones, Baumgartner (2006), são complementares na aplicabilidade da tomada de decisão orçamentária desta autarquia. Assim, sugere-se que novas pesquisas sejam realizadas, não só em autarquias, mas em sistemas orçamentários públicos em geral, com o intuito de testar essa proposição.

\section{REFERÊNCIAS}

ABREU, W. M. de; GOMES, R. C. Orçamento público: análise da formulação de estratégias sob a perspectiva do planejamento emancipatório e desenvolvimentista. Revista do Serviço Público. Brasília 61 (3): 269-286 Jul/Set 2010.

ABREU, W. M. de; GOMES, R. C. O orçamento público brasileiro e a perspectiva emancipatória: existem evidências empíricas que sustentam esta aproximação?. Revista de Administração Pública, v. 47, n. 2, p. 515-540, 2013.

BARCELOS, C. L. K. Quinze Anos sem Aaron Wildavsky: recordando lições valiosas. Enapg, 2008.

COHEN, M. D., MARCH, J. G., OLSEN, J. P. A Garbage Can Model of Organizational Choice. Administrative Science Quarterly, vol. 17, n. 1, 1972, pp. 01-25.

BIN, D.; CASTOR, B. V. J. Racionalidade e Política no Processo Decisório: estudo sobre orçamento em uma organização estatal. Revista de Administração Contemporânea, v. 11, n. 3, Jul./Set.2007: 35-56.

DAVIS, O. A.; DEMPSTER, M. A. H.; WILDAVSKY, A. B. A Theory of the Budgetary Process. The American Political Science Review, V. 60, N. 3. 1966, pp. 529-547.

FORTIS, M. F. de A. Orçamento orientado a resultados: instrumento de fortalecimento democrático na América Latina. Revista do Serviço Público. Brasília. 60 (2): 125-140 Abr/Jun 2009.

GIACOMONI, J. Orçamento Público. 8 ed. São Paulo: Atlas, 1998.

KINGDON, J. W. Agendas, alternatives, and public policies. Boston: Little, Brown, 1984.

LINDBLOM, C. E. Muddlingthrough 1: A ciência da decisão incremental. (1959) In: HEIDEMANN, F. G., SALM, J. F. (orgs.). Políticas públicas e desenvolvimento: bases epistemológicas e modelos de análise.2. ed. Brasília: Ed. Universidade de Brasília, 2010. 
NEIVA, V. M.; LIMA, N.; ABREU, W. M. de.Orçamento Público Brasileiro: em busca de enigmas decisórios. Textos para discussão, n. 005, Tesouro Nacional, 2012.

PADGETT, J. F. Bounded rationality in budgetary research. The American Political Science Review, V. 74, N. 2. 1980, pp. 354-372.

TRUE, J. L.; JONES, B. D.; BAUMGARTNER, F. R. Punctuated Equilibrium Theory Explaining Stability and Change in Public Policymaking. In. SABATIER, Paul. Theories of the policy process. 2 ed. 2006.

VALLE, A. G. R. M. do; FROSSARD, L. B. de M.; CRUZ, T. M. E.da. Nova agenda de pesquisa para a área de estudos orçamentários no Brasil: as contribuições do modelo incremental, do modelo de julgamento seriado, do modelo MS (fluxos múltiplos) e do modelo de equilíbrio pontilhado (terremoto)". ENAPG, 2010. Vitória/ES - 28 a 30 de novembro de 2010 . 